\title{
ОБЯЗАТЕЛЬНЫЕ АКТАНТЫ ГЛАГОЛА В ПЕРСИДСКОМ ЯЗЫКЕ И СПОСОБЫ ИХ ВЫРАЖЕНИЯ НА РУССКИЙ ЯЗЫК
}

\section{MANDATORY ACTANTS OF THE VERB IN PERSIAN AND WAYS OF EXPRESSING THEM IN RUSSIAN \\ Reza-Morad Sahra'i K. Buiakevych}

Summary: In the Dependency Grammar of Persian language eight obligatory verb argument are distinguished: subject, direct object, genitive complement, indirect object, object complement, subject complement, adverbial complement and clause complement. The obligatory presence of these arguments in the sentence is due to the valency verb structure. In this article we tried to analyze the syntactic features of each argument and the types of grammatical relationship between the verb and its arguments and also pointed out the main ways of expressing Persian obligatory arguments into Russian.

Keywords: subject, direct object, genitive complement, indirect object, object complement, subject complement, adverbial complement, clause complement

\author{
Реза-Морад Caxpau \\ К.филол.н., профессор, Университет \\ им. Алламе Табатабаи, Иран, г. Тегеран \\ rezasahraee@yahoo.com \\ Буякевич Кристина Анатольевна \\ Аспирант, Университет им. Алламе Табатабаи, \\ Иран, г. Тегеран \\ kristinaicompany@ukr.net
}

Аннотация: В Грамматике зависимостей персидского языка выделяют восемь обязательных актантов: подлежащее, прямое дополнение, генитивный актант, непрямое дополнение, объектный актант, субъектный актант, обстоятельственный актант и сентенциальный актант. Обязательное наличие этих актантов в предложении обусловлено валентностной структурой глагола. В данной статье мы попытались проанализировать синтаксические особенности каждого актанта и типы грамматических связей глагола с этими актантами, а также указали на основные способы выражения обязательных актантов персидского языка на русский язык.

Ключевые слова: подлежащее, прямое дополнение, генитивный актант, непрямое дополнение, объектный актант, субъектный актант, обстоятельственный актант, сентенциальный актант.

[7]. О. Табибзаде подлежащее в персидском языке рассматривает с двух позиций: с личными и безличными глаголами. Подлежащее безличных глаголов бывает двух видов: опущенное и нулевое. Опущенное подлежащее имеет место в валентностной структуре глагола, но всегда опускается. Нулевое подлежащее встречается в безличных предложениях, в которых вообще отсутствует подлежащее и поэтому в данной статье мы не будет рассматривать подлежащее безличных глаголов. Что же касается подлежащего личных глаголов, то необходимо отметить, что персидский язык - представитель pro-drop languages, в связи с этим подлежащее личных глаголов может опускаться, т.е. его наличие не является обязательным и может быть опущено, особенно, если оно выраженно личными местоимениями. Такая же тенденция к опущению подлежащего есть и в русском языке, например, Fardā miram Tehrān'Завтра еду в Тегеран'. Однако наличие подлежащего и в русском и в персидском языках отображается в виде суффикса - личного окончания глагола. В отличие от русского языка, подлежащее в персидском языке не имеет морфологически выраженного падежного признака и рода, поэтому важнейшим показателем подлежащего является его морфологическое согласование с глаголом в лице и числе, так как в персидском языке ни один другой актант не согласовывается с глаголом. В качестве примера приведем согласование с глаголом хundan 'читать' в настоящем времени. Отметим, 
что для образования настоящего времени используется следующая формула: приставка настоящего времени mi+ основа настоящего времени глагола ('xun')+ личные окончания.

\begin{tabular}{|c|c|c|c|c|c|}
\hline (1) & лицо & \multicolumn{2}{|c|}{ единственное число } & \multicolumn{2}{c|}{ множественное число } \\
\cline { 2 - 6 } & $1-\mathrm{e}$ & mi-xun-am & чита-ю & mi-xun-im & чита-ем \\
\hline \multirow{2}{*}{$2-\mathrm{e}$} & mi-xun-i & чита-ешь & mi-xun-id & чита-ете \\
\hline \multirow{2}{*}{$3-\mathrm{e}$} & mi-xun-ad & чита-ет & mi-xun-and & чита-ют \\
\hline
\end{tabular}

Из примера (1) видим, что подлежащее формально выражается личными окончаниями глагола, т.е. согласуется с ним в лице и числе. Стоит отметить, что согласование в лице и числе подлежащего с глаголом в персидском языке прослеживается во всех временных формах, но в русском не всегда так, например, форма лица есть только у глаголов настоящего и будущего времени, глаголы прошедшего времени изменяются только по числам: 'читал' и 'читали', а в единственном числе могут изменяться ещё и по родам: 'читал,' ‘читала,' ‘читало'.

\section{Прямое Аополнение (Direct Object)}

Прямое дополнение в персидском языке выражено именной группой и его формальным показателем является послелог -rā, который следует за именной группой. Однако этот послелогупотребляется только в том случае, если прямое дополнение обозначает определенные, конкретные или известные предметы и явления (например, выраженные именами собственными, местоимениями). Таким образом, в персидском языке мы имеем дело с дифференциальным маркированием объекта: прямое дополнение, оформленное послелогом -rā считается референтным, а дополнение без послелога - нереферентным, то есть на маркирование/немаркирование прямого дополнения влияет определенность/неопределенность и одушевленность \неодушевленность объекта [2]. Необходимо отметить, что наличие или отсутствие послелога с прямым дополнением не отображается при переводе на русский язык и чаще всего оформляется винительным падежом. Например:

\begin{tabular}{|c|c|c|c|}
\hline \multirow[t]{4}{*}{ (2) } & Man & Ahmad-rā & mi-šenās-am. \\
\hline & Sub: 1st, sing & D0 + postposition -rā & V: cont, pres, sub affix 1st, sing \\
\hline & я & Ахмада & знаю \\
\hline & \multicolumn{3}{|c|}{ Я знаю Ахмада. } \\
\hline
\end{tabular}

\begin{tabular}{|c|c|c|c|}
\hline (3) & Man & ketāb & xund-am. \\
\cline { 2 - 4 } & Sub: 1st, sing & D0 & V: past, sub affix 1st, sing \\
\cline { 2 - 4 } & я & \multicolumn{3}{|c|}{ книгу } & прочитал \\
\hline & \multicolumn{3}{|c|}{ Я прочитал книгу. } \\
\hline
\end{tabular}

В примере (2) прямое дополнение референтное - имя собственное, поэтому оформленное послелогом, в при- мере (3) нереферентное, то есть выражает объект как представитель всего класса, а не какой-либо конкретный. Оба эти дополнения при переводе на русский язык оформляются винительным падежом, вне зависимости от определенности \неопределенности объекта.

Иногда прямое дополнение в персидском языке при переводе на русский может оформляться родительным падежом. Это касается тех случаев, когда при сказуемом имеется отрицание [1]. Например:

\begin{tabular}{|c|c|c|c|}
\hline (4) & $U$ & in ketāb-rā & na-did. \\
\cline { 2 - 4 } & $\begin{array}{c}\text { Sub: } 3 r d, \\
\text { sing }\end{array}$ & $\begin{array}{c}\text { D0 + postposition } \\
\text {-rāa }\end{array}$ & $\begin{array}{c}\text { V: negat, past, } \\
\text { null sub affix 3rd, sing }\end{array}$ \\
\cline { 2 - 4 } & онlона & этой книги & не видел(а) \\
\cline { 2 - 4 } & \multicolumn{3}{|c|}{ ОнІона не видел(а) этой книги. } \\
\hline
\end{tabular}

Как видим, в персидском языке связь сказуемого с прямым дополнением осуществляется посредством управления при помощи послелога или без него, при этом дополнение обычно находится в препозиции к своему глаголу. При переводе персидских прямых дополнений на русский язык связь сказуемого с дополнением осуществляется при помощи беспредложного управления и в большинстве случаев оформляется винительным, а при отрицательном сказуемом - родительным падежами и будет находиться в постпозиции относительно глагола.

\section{Генитивный актант (Genitive Complement)}

Это единственный актант в персидском языке, который не употребляется с простыми глаголами (т.е. состоящими из одного слова), а встречается в валентностной структуре только некоторых сложных глаголов. Этот вид глагола представляет собой сочетание простого глагола (или компонирующего) и неглагольного компонента (например, имени существительного). Примером такого глагола, который принимает генитивный актант, является глагол рāsox dādan, который состоит из компонирующего глагола dādan 'давать' и неглагольного компонента pāsox 'ответ' и переводится как 'отвечать' (дословно 'давать ответ'). Генитивный актант - это такой вид актанта, который помещается между двумя компонентами сложного глагола посредством подчинительного вида связи, при котором подчиняющее слово (неглагольный компонент сложного глагола) связывается с подчиненным словом (генитивным актантом) при помощи изафета безударного грамматического показателя -е (-уе после гласного). Иными словами, происходит расщепление сложного глагола актантом. В отечественной иранистике данная конструкция называется «Рамочная конструкция сказуемого». Ю.А. Рубинчик [4, с. 445] определяет рамочную конструкцию следующим образом: «Это дистантное построение группы сказуемого, при котором его компоненты находятся в разобщенном состоянии и между 
ними помещаются второстепенные члены, развивающие и уточняющие значение всего сказуемого в целом». Также в зарубежной иранистике есть мнение о том, что генитивный актант - это аргумент именной части глагола или же, например, прямое дополнение, которое может связываться с глаголом в форме подчинительной связи, т.е. посредством изафета с его именной частью. Однако это довольно спорный вопрос и в данном исследовании мы будем придерживаться точки зрения иранских грамматистов. Согласно теории О. Табибзаде генитивный актант является полноценным актантом некоторых сложных глаголов, подобно прямому или непрямому дополнению, однако отличается своей позицией в предложении - помещается внутри глагола и способом связи - подчинение при помощи изафета [6]. Рассмотрим следующий пример:

\begin{tabular}{|c|c|c|}
\hline (5) & Dišab & sefäreš - e pitzā dād-am. \\
\cline { 2 - 3 } & Adverb & $\begin{array}{c}\text { Compound predicate: nominal component + ezafe particle + } \\
\text { genitive complement + V: past, sub affix 1st sing }\end{array}$ \\
\cline { 2 - 3 } & вчера & заказ пиццы сделал(а) \\
\cline { 2 - 3 } & \multicolumn{2}{|}{ Я вчера заказал(а) пиццу. } \\
\hline
\end{tabular}

В данном примере глагол sefāreš dādan дословно переводится как 'делать заказ', а его генитивный актант pitzā 'пицца' помещается между двух компонентов глагола и связывается с именной частью посредством изафета -е, при этом между именной частью глагола и его актантом устанавливается связь подобно определения с определяемым, отсюда и название этого актанта - генитивный. Персидские сложные глаголы переводятся на русский язык простыми глаголами, т.е. состоящими из одной лексемы, а генитивный актант чаще всего выражен прямым дополнением. Например, глагол darxāst kardan дословно переводится 'делать просьбу' на русский язык переводится глаголом 'просить', а сочетание darxāst-e komak kardan (дословно 'просьбу помощи делать') будет переводиться как'просить помощи'. Есть в русском языке и другие средства, с помощью которых можно переводить персидский генитивный актант, но эти случаи более редкие и требуют подробного описания, поэтому в данной статье мы указали только самый распространенный способ перевода этого актанта на русский язык, т.е. посредством прямого дополнения.

\section{Непрямое Аополнение (Indirect Object)}

В персидском языке непрямое дополнение выступает в форме предложной группы, а управление осуществляется при помощи простых и сложных (состоящих из двух и реже трех слов) предлогов. При переводе этого вида дополнений на русский, они могут передаваться различными средствами, т.е. могут быть выражены с предлогом и без него и оформляться разными видами падежей. О. Табибзаде в рамках Грамматики зависимостей отмечает, что в валентностной структуре глагола, имеющей в своем составе непрямое дополнение, необ- ходимо указывать и предлог, например, валентностная структура глагола dars dādan 'преподавать, учить' выглядит следующим образом <Sub, DO (+ -rā), IO (preposition az)>. Рассмотрим следующие примеры:

\begin{tabular}{|c|c|c|c|c|}
\hline \multirow[t]{4}{*}{ (6) } & U & bemā & tārix & dars mi-dād. \\
\hline & $\begin{array}{c}\text { Sub: 3rd, } \\
\text { sing }\end{array}$ & $\begin{array}{c}10+ \\
\text { preposition be }\end{array}$ & DO & $\begin{array}{c}\text { Compound verb: } \\
\text { nominal component + } \\
\text { V: cont, null sub affix } \\
\text { 3rd, sing }\end{array}$ \\
\hline & он\она & нам & историю & урок давал(а) \\
\hline & \multicolumn{4}{|c|}{ Он\она преподавал(а) нам историю. } \\
\hline
\end{tabular}

Как видим из примера (6), непрямое дополнение выраженно в форме предложной группы be mā и управляется предлогом bе (употребляется при обозначении адресата или лица, на которое направлено действие). В русском языке данная структура передается дательным падежом без предлога - 'нам', т.е. формой дательного падежа от местоимения 'мы'.

\begin{tabular}{|c|c|c|c|}
\hline \multirow[t]{4}{*}{ (7) } & Šomā & bexodā & etteqäd där-id. \\
\hline & $\begin{array}{c}\text { Sub: 2nd, } \\
\mathrm{pl}\end{array}$ & $\begin{array}{c}10+ \\
\text { preposition be }\end{array}$ & $\begin{array}{c}\text { Compound verb: nominal component + } \\
\text { V: pres, sub affix } 2 \mathrm{nd}, \mathrm{pl}\end{array}$ \\
\hline & Вы & в бога & веру имеете \\
\hline & \multicolumn{3}{|c|}{ Вы верите в бога. } \\
\hline
\end{tabular}

В примере (7) непрямое дополнение также оформлено предлогом be, однако на русский язык оно переводится дополнением в винительном падеже с предлогом 'в'.

\begin{tabular}{|c|c|c|c|c|}
\hline (8) & In äghā & bače-hā-rā & az ätaš & nejāt-dād. \\
\cline { 2 - 5 } & $\begin{array}{c}\text { Sub: 3rd, } \\
\text { sing }\end{array}$ & $\begin{array}{c}\text { D0 + pl affix }+ \\
\text { postposition } \\
-r \bar{a}\end{array}$ & $\begin{array}{c}10+ \\
\text { preposition } \\
a z\end{array}$ & $\begin{array}{c}\text { Compound verb: } \\
\text { nominal component + } \\
\text { V: past, null sub affix } \\
\text { 3rd, sing }\end{array}$ \\
\cline { 2 - 5 } & $\begin{array}{c}\text { этот } \\
\text { мужчина }\end{array}$ & детей & от пожара & спасение дал \\
\cline { 2 - 5 } & \multicolumn{4}{|c|}{ Этот мужчина спас детей от пожара. } \\
\hline
\end{tabular}

Непрямое дополнение в примере (8) az ātaš имеет предлог az (употребляется при указании на освобождение, избавления от чего-либо) при переводе на русский оформляется родительным падежом с предлогом 'от'.

\begin{tabular}{|c|c|c|c|c|}
\hline \multirow[t]{3}{*}{ (9) } & Man & in mouzu-rā & bā šomā & bahs na-mi-kon-am. \\
\hline & $\begin{array}{c}\text { Sub: 1st, } \\
\text { sing }\end{array}$ & $\begin{array}{c}\text { D0: }+ \\
\text { postposition } \\
-r \bar{a}\end{array}$ & $\begin{array}{c}10+ \\
\text { preposition } \\
b \bar{a}\end{array}$ & $\begin{array}{c}\text { Compound verb: } \\
\text { nominal component + } \\
\text { V: neg, cont, pres, sub } \\
\text { affix 1st, sing }\end{array}$ \\
\hline & Я & эту тему & с вами & $\begin{array}{c}\text { обсуждение не буду } \\
\text { делать }\end{array}$ \\
\hline
\end{tabular}


В примере (9) непрямое дополнение bā šomā функционирует с предлогом $b \bar{a}$ (который используется при обозначении совместности, участия в одном и том же деле) и передается на русский язык дополнением в форме творительного падежа с предлогом.

Как видим, в персидском языке управление непрямым дополнением может быть только предложным и находящимся в препозиции к глаголу, но в русском оно может быть как предложным, так и беспредложным, а также оформляется разными видами падежей (дательный, винительный, родительный, творительный) [5] и располагается в постпозиции относительно глагола.

\section{Объектный актант (Object Complement)}

Это такой вид актанта в персидском языке, который употребляется после прямого и реже непрямого дополнения и считается его аргументом, так как поясняет или уточняет дополнение. Объектный актант не имеет никаких морфологических показателей и определяется только своей позицией в предложении - следует за дополнением и находится в препозиции к глаголу. Необходимо отметить, что если этот актант описывает прямое дополнение, то это дополнение всегда будет оформляться послелогом -rā, так как уже считается референтным. Глаголы, которые принимают этот актант в качестве обязательного, в персидском языке немногочисленны, например: nāmidan, nām dādan, goftan 'называть, именовать', pandāštan 'полагать, считать', etlāq kardan 'называть, присваивать имя', laqab dādan 'прозывать, давать прозвище'[8]. Рассмотрим следующие примеры:

\begin{tabular}{|c|c|c|c|c|}
\hline (10) & $\bar{A} n h \bar{a}$ & pesar-exod-rā & Ivān & nämid-and. \\
\cline { 2 - 5 } & $\begin{array}{c}\text { Sub: } 3 r d, \\
\mathrm{pl}\end{array}$ & $\begin{array}{c}\text { D0: }+ \\
\text { postposition } \\
-r \bar{a}\end{array}$ & $\begin{array}{c}\text { 0bject } \\
\text { Complement }\end{array}$ & $\begin{array}{c}\text { V: past, sub affix } \\
\text { 3rd, pl }\end{array}$ \\
\cline { 2 - 5 } & они & Сына своего & Иван & назвали \\
\cline { 2 - 5 } & \multicolumn{4}{|c|}{ Они назвали своего сына Иваном. } \\
\hline
\end{tabular}

\begin{tabular}{|c|c|c|c|c|}
\hline (11) & $M \bar{a}$ & beu & ostād & mi-goft-im. \\
\cline { 2 - 5 } & $\begin{array}{c}\text { Sub: 2nd, } \\
\mathrm{pl}\end{array}$ & $\begin{array}{c}10+ \\
\text { preposition } \\
\text { be }\end{array}$ & $\begin{array}{c}\text { Object } \\
\text { Complement }\end{array}$ & $\begin{array}{c}\text { V: cont, past, sub } \\
\text { affix 2nd, pl }\end{array}$ \\
\cline { 2 - 5 } & его & мастер & называли \\
\cline { 2 - 5 } & \multicolumn{4}{|c|}{ Мы называли его мастером. } \\
\hline
\end{tabular}

Как видим из примеров глаголы nämidan и goftan в значении 'называть' требуют наличия объектного актанта, который выражен именными группами Ivān u ostād, однако в примере (10) этот актант поясняет прямое референтное дополнение, а в примере (11) - непрямое дополнение, выраженное предложной группой. На русский язык этот актант в подобных конструкциях обычно передается обстоятельством, поясняющим дополнение и чаще всего выражено существительным в творительном падеже без предлога.

\section{Субъектный актант (Subject Complement)}

В персидском языке - это именная часть составного именного сказуемого, которая является обязательным актантом для некоторых связочных глаголов, проявляя дополнительное или новое значение подлежащего, тем самым объясняя свое название. Этот актант не имеет никаких морфологических показателей и определяется лишь своим местом в предложении - помещается между связочным глаголом и подлежащим, а в русском языке именная часть сказуемого согласуется с подлежащим в числе и роде [3]. Необходимо отметить, что в персидском языке имена обычно не выступают в функции сказуемого без глагольной связки, поэтому предложения с именным сказуемым состоят как минимум из трех синтаксических единиц, а в русском языке - как минимум из двух (в случае нулевой связки), т.е. в персидском языке наличие глагол-связки обязательное условие для построения грамматически правильного предложения. Наиболее распространенными связочными глаголами являются hast 'есть, имеется', budan 'быть, существовать, находиться' и šodan 'быть, становиться'. Роль этого актанта в предложении может выполнять именная, наречная, предложная группы или группа прилагательного [8] и поэтому перевод этого актанта на русский язык осуществляется различными способами, в данной статье мы укажем только некоторые из них. Например:

\begin{tabular}{|c|c|c|c|}
\hline (12) & Man & moalem-e zabān-e rusi & hast-am. \\
\cline { 2 - 4 } & $\begin{array}{c}\text { Sub: 1st, } \\
\text { sing }\end{array}$ & Subject Predicate & $\begin{array}{c}\text { Linking verb: pres, sub affix } \\
\text { 1st, sing }\end{array}$ \\
\cline { 2 - 4 } & я & $\begin{array}{c}\text { учитель русского } \\
\text { языка }\end{array}$ & есть \\
\cline { 2 - 4 } & \multicolumn{3}{|c|}{ Я-учитель русского языка. } \\
\hline
\end{tabular}

В примере (12) глагол-связка hast требует предикатива к подлежащему, который выражен именной группой, поясняющей подлежащее. При переводе подобных конструкций на русский язык в именном сказуемом есть нулевая связка, материально не выраженная и служащая показателем настоящего времени изъявительного наклонения и поэтому между подлежащим и сказуемым ставится тире. Именная часть сказуемого выражена именной группой в форме именительного падежа.

\begin{tabular}{|c|c|c|c|}
\hline (13) & Un sāxtemān & besyār mohkam & bud. \\
\cline { 2 - 4 } & Sub: 3rd, sing & Subject Predicate & $\begin{array}{c}\text { Linking verb: past, null sub } \\
\text { affix 3rd, sing }\end{array}$ \\
\cline { 2 - 4 } & то здание & очень прочный & было \\
\hline & \multicolumn{3}{|c|}{ То здание было очень прочным. } \\
\hline
\end{tabular}

В примере (13) именная часть сказуемого выражена 
прилагательной группой, а связывающий глагол budan 'быть' стоит в форме прошедшего времени. При переводе на русский язык именная часть сказуемого, т.е. группа прилагательного, будет в творительном падеже и поскольку глагол-связка стоит в прошедшем времени, то не может быть опущена.

\begin{tabular}{|c|c|c|c|}
\hline (14) & Maryam & dar xāne & ast. \\
\cline { 2 - 4 } & Sub: 3rd, sing & Subject Predicate & $\begin{array}{c}\text { Linking verb: pres, sub affix } \\
\text { 3rd, sing }\end{array}$ \\
\cline { 2 - 4 } & Марьям & дома & есть \\
\cline { 2 - 4 } & \multicolumn{3}{|c|}{ Марьям дома. } \\
\hline
\end{tabular}

В примере (14) предложная группа выступает в функции именной части сказуемого и на русский язык переводится обстоятельством места, выраженным наречием.

\begin{tabular}{|c|c|c|c|}
\hline (15) & Senn-eu & bištar az senn-e man & ast. \\
\cline { 2 - 4 } & $\begin{array}{c}\text { Sub: } 3 r d, \\
\text { sing }\end{array}$ & Subject Predicate & $\begin{array}{c}\text { Linking verb: pres, sub } \\
\text { affix 3rd, sing }\end{array}$ \\
\cline { 2 - 4 } & его возраст & $\begin{array}{c}\text { больше моего } \\
\text { возраста }\end{array}$ & есть \\
\cline { 2 - 4 } & \multicolumn{3}{|c|}{ Он старше меня. } \\
\hline
\end{tabular}

В примере (15) именная часть сказуемого выражена наречной группой и на русский язык переводится составным именным сказуемым, в котором именную часть выполняет прилагательное в форме сравнительной степени.

\section{Обстоятельственный актант (Adverbial Complement)}

В персидском языке этот вид актанта выражен наречной группой и считается наименее употребимым, так как чаще всего наречные группы функционируют в предложении в качестве сирконстантов - необязательных элементов. Однако есть ограниченное число глаголов, в валентностной структуре которых обстоятельственный актант является обязательным. В качестве примера рассмотрим два таких глагола raftār kardan 'поступать, вести себя' и arzidan 'стоить, иметь цену':

\begin{tabular}{|c|c|c|c|}
\hline (16) & $U$ & moadabāne & raftär kard. \\
\cline { 2 - 4 } & Sub:3rd, sing & $\begin{array}{c}\text { Adverbial } \\
\text { Compement }\end{array}$ & $\begin{array}{c}\text { Compound verb: nominal } \\
\text { component + V: past, null } \\
\text { sub affix 3rd, sing }\end{array}$ \\
\cline { 2 - 4 } & онІона & вежливо & вел(а) себя \\
\cline { 2 - 4 } & \multicolumn{3}{|c|}{ ОнІона вел(а) себя вежливо. } \\
\hline
\end{tabular}

\begin{tabular}{|c|c|c|c|}
\hline (17) & In xāne & xeili & mi-arz-ad. \\
\cline { 2 - 4 } & Sub: 3rd, sing & $\begin{array}{c}\text { Adverbial } \\
\text { Complement }\end{array}$ & V: pres, sub affix 3rd, sing \\
\cline { 2 - 4 } & этот дом & много & стоит \\
\cline { 2 - 4 } & \multicolumn{3}{|c|}{ Этот дом стоит дорого. } \\
\hline
\end{tabular}

Обычно с переводом этого актанта на русский язык не возникает трудностей, потому что он почти всегда переводится обстоятельствами, выраженные наречиями, например, обстоятельствами образа действия, как в примере (16) 'вежливо', или меры, стоимости, как в примере (17) 'много\дорого'.

\section{Сентенциальный актант (Clause Complement)}

Этот актант обычно выражен придаточным предложением и является обязательным для некоторых глаголов, например, goftan 'говорить, сказать', ха̄heš kardan 'просить'. Средство связи этого актанта с глаголом - союз $k e$, который является формальным показателем подчиненности одного предложения другому, однако сентенциальный актант может оформляться и бессоюзно. Стоит отметить, что это единственный актант в персидском языке, который находится в постпозиции по отношению к своему глаголу. Это объясняется его «тяжестью», т.е. сентенциальный актант является синтаксически тяжелее, чем именные актанты, поэтому и в русском и в персидском языке этот актант помещается в конец предложения. Рассмотрим следующие примеры:

\begin{tabular}{|c|c|c|c|}
\hline (18) & $\bar{A} n h \bar{a}$ & goft-and & ke fardā be-rav-and. \\
\cline { 2 - 4 } & Sub: 3rd, pl & $\begin{array}{c}\text { V: past, sub affix } \\
\text { 3rd, pl }\end{array}$ & $\begin{array}{c}\text { Complementizer + } \\
\text { Complement clause }\end{array}$ \\
\cline { 2 - 4 } & они & сказали & что завтра уедут \\
\cline { 2 - 4 } & \multicolumn{3}{|c|}{ Они сказали, что уедут завтра. } \\
\hline
\end{tabular}

Как видим из примера (18) сентенциальный актант выражен придаточным предложением с союзом kе и на русский язык данная конструкция также переводится придаточным предложением, оформленным подчинительным союзом 'что'.

\begin{tabular}{|c|c|c|c|l|}
\hline (19) & Mādar & az man & xāheš kard & ke bi-a--yam. \\
\cline { 2 - 5 } & $\begin{array}{c}\text { Sub: 3rd, } \\
\text { sing }\end{array}$ & $\begin{array}{c}\text { I0+ } \\
\text { preposition az }\end{array}$ & $\begin{array}{c}\text { V: past, sub } \\
\text { affix 3rd, sing }\end{array}$ & $\begin{array}{l}\text { Complementizer + } \\
\text { Complement clause }\end{array}$ \\
\cline { 2 - 5 } & мама & меня & попросила & чтобы (я) приехал (а) \\
\hline \multicolumn{4}{|c|}{ Мама попросила меня приехать। } \\
Мама попросила, чтобы я приехал(а).
\end{tabular}

Сентенциальный актант в примере (19) на русский язык может переводиться двумя способами:

1). Инфинитивом в роли косвенного дополнения.

2). Придаточным предложением, вводимым союзом 'чтобы'.

\section{Зак^ючение}

В данной статье мы проанализировали основные синтаксические особенности восьми обязательных актантов в персидском языке. Мы также рассмотрели подчинительные средства связи глагола со своими ак- 
тантами: при помощи согласования (с подлежащим), управления (посредством предлогов и послелога -rā) (с прямым и непрямым дополнением), примыкания (с объектным, субъектным, обстоятельственным и сентенциальным актантами) и изафетной конструкции (с генитивным актантом). Как видим, персидский язык, являясь языком аналитического строя, имеет более ограниченные морфологические показатели свои актантов, в частности не имеет падежных показателей, поэтому перевод персидских актантов на русский язык осуществляется различными средствами, например, предложная группа в функции непрямого дополнения при переводе на русский язык может быть выражена как предложной, так и непредложной группой и иметь разные виды падежей. Мы считаем, что подобные особенности выражения персидских глагольных актантов на русский язык может быть применимы как в сфере перевода, так и в сфере изучения этих двух языков.

\section{ЛИТЕРАТУРА}

1. Валгина Н.С. Современный русский язык. Синтаксис : учеб. для вузов рек. МО РФ. 4-е изд., испр. М. : Высшая школа, 2003.

2. Выдрин А.П. Прямое дополнение и сложные глаголы в современном персидском языке: грамматический и лексикографический аспекты // Магистерская диссертация. Санкт-Петербург, 2006.

3. Розенталь Д.Э., Голуб И.Б., Теленкова М.А. Современный русский язык. - 7-е изд. - М.: Айрис-пресс, 2005.

4. Рубинчик Ю.А. Грамматика современного персидского литературного языка. - М.: Восточная литература РАН. - 2001.

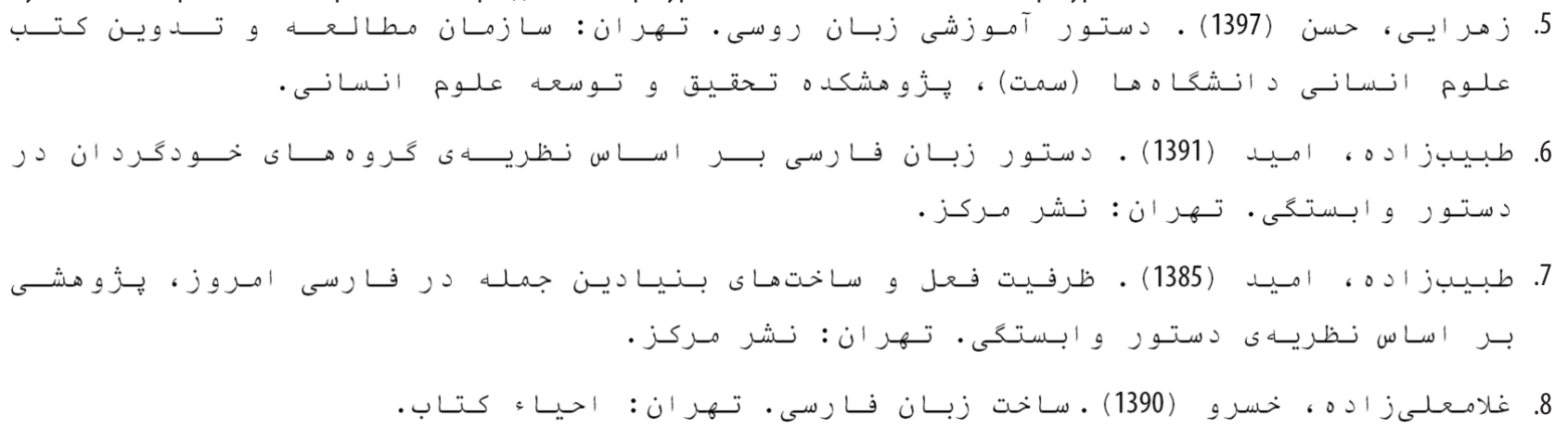

